http://jmscr.igmpublication.org/home/ ISSN (e)-2347-176x ISSN (p) 2455-0450 crossref DOI: https://dx.doi.org/10.18535/jmscr/v9i8.20

\title{
Emergency laparotomy for necrotizing enterocolitis in a newborn
}

\author{
Authors \\ Dr Manvi Katoch ${ }^{1}$, Dr Tanvi Katoch ${ }^{2}$ \\ ${ }^{1}$ Anaesthesiologist, Zonal Hospital, Dharamshala, H.P. \\ ${ }^{2}$ Senior resident, Department of Obstetrics and Gynecology, PGI, Chandigarh \\ *Corresponding Author \\ Dr Tanvi Katoch \\ Senior Resident, Department of Obstetrics and Gynecology, PGI, Chandigarh
}

\begin{abstract}
Necrotizing enterocolitis (NEC) is a major cause of morbidity and mortality in NICU survivors. It is predominantly seen in premature formula fed infants. The symptoms may include fever, lethargy, abdominal distension, nausea, vomiting, bloody stools and poor feeding. The mainstay of treatment is discontinuation of oral feeds, nasogastric decompression, with IV feeds and antibiotics along with supportive therapy. Here, we present a case report of a very low birth weight (VLBW) premature infant with NEC.
\end{abstract}

Keywords: necrotizing enterocolitis (NEC), preterm child, abdominal distention.

\section{Introduction}

Necrotizing enterocolitis isa serious condition involving intestines and mainly affects preterm children. It has complex and multifactorial etiology, and it is most commonly found in preterm infants. NEC occurs when bacteria invade the intestinal wall causing its infection and inflammation. In some cases, bowel perforation can also occur. If not treated, it can lead to mortality. The treatment of necrotizing enterocolitis is mostly clinical, but surgery can be performed in some cases of complications with decline in child's general being.

\section{Case Report}

A one day baby was admitted to the pediatrics department in view of very low birth weight. It was a preterm vaginal delivery in a private hospital at POG $36^{+3}$ weeks, and baby cried immediately after birth. Birth weight of baby was 1,345 grams. On presentation, baby was in cold stress with temperature 36.1 degree $\mathrm{C}$

Vitals were as follows- HR- 160/min, RR- 80/ min, peripheral pulses were palpable, $\mathrm{SpO} 2-90 \%$ on room air, CRT <3sec, RBS- $17 \mathrm{mg} / \mathrm{dl}$. Systemic examination was within normal limit. Abdomen was soft with no organomegaly. Neonatal reflexes were normal.

Diagnosis was made as preterm child at $36^{+3}$ weeks with very low birth weight (VLBW) with IUGR with cold stress, respiratory distress with hypoglycemia.

The child was kept in radiant warmer and given IV D10\% bolus for hypoglycemia along with its maintenance infusion. Antibiotics inj. piptaz and inj.amikacin were started.

On day 2 of admission, SpO2-95\%, RR-54/min, peripheral pulses were palpable. Orogastric feeds 
were started every 2 hourly along with blood sugar and vitals monitoring.

On day 5 of admission, gastric aspirate of 5-10 ml was done. Child had not passed stool in last 24hours. On examination, gangrene was present on right index and middle finger. Oral feed was withheld. Antibiotics and IV feed as GIR infusion were started @6mg/ $\mathrm{kg} / \mathrm{min}$ to maintain blood sugar and was tapered accordingly. Blood culture showed candida albicans for which Inj. Amphotericin B was started intravenously.

On day7 of admission, child had passive upper gastrointestinal bleed with bilious aspirate. Abdomen was distended and soft [Figure 1].Abdominal X-Ray was done which was suggestive of NEC stage 1 [Figure 2]. Oral feed was stopped and antibiotics were continued along with supportive therapy as IV fluids for nutrition, electrolytes.

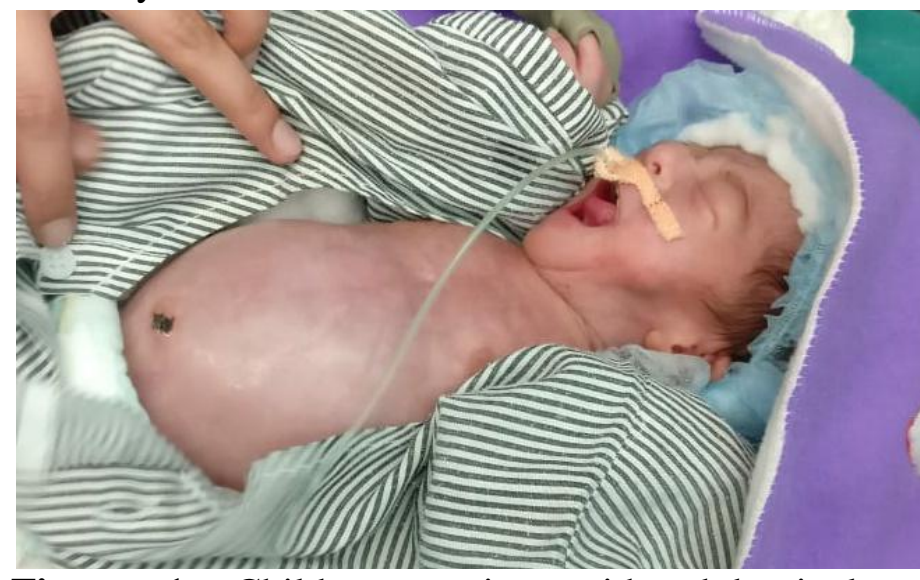

Figure 1: Child presenting with abdominal distention

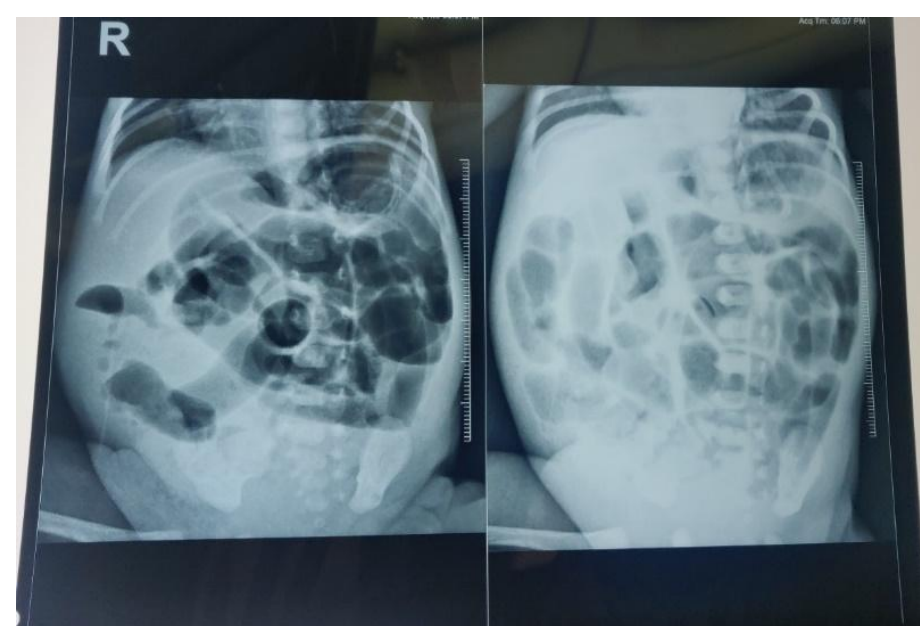

Figure 2: Abdominal X-ray showing pneumatosis intestinalis with distention of bowel loops
Child was planned for emergency laparotomy by pediatric surgeon for sub-acute intestinal obstruction with distended abdomen. Child was taken to operation theatre. Surgery was performed under general anaesthesia [Figure 3].

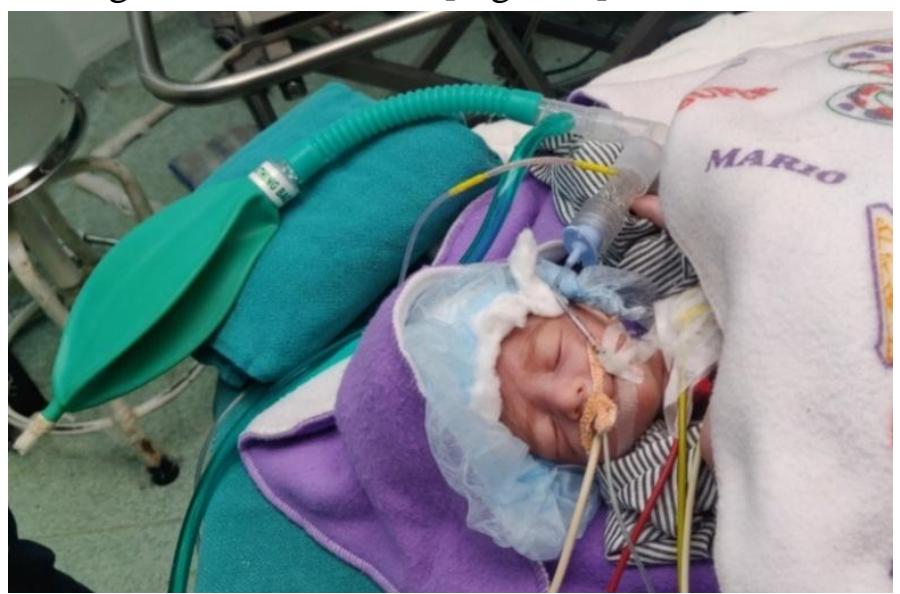

Figure 3: Child in OT under general anaesthesia

Operative findings were as follows: tense duplication cyst was found which shared common wall with distal ileum alongwith compression of distal ileal lumen.proximal ileum was dilated and healthy. Cyst was aspirated with no bowel contents in it. After decompression, distal ileum patency was ensured. Duplication cyst was excised and proximal bowel was decompressed.

Child was then shifted to NICU for monitoring. Antibiotics and IV fluids were started with vitals monitoring. Child started recovering in next 20 days and was shifted to pediatric ward on getting stabilized.

\section{Discussion}

Necrotizing enterocolitis is a gastrointestinal inflammatory disorder, mainly affecting preterm and low birth weight infants, which manifests exaggerated and severe, thus leading to increased risk of pathogenic bacterial invasion. ${ }^{[1,2]}$

Morbidity and mortality are more in premature infants. The pathogenesis is complex and multifactorial. Major factors responsible for it are bacterial colonisation of intestine, formula feeding and prematurity. ${ }^{[3,4]}$

Child may present with symptoms of abdominal distention, pain, nausea, vomiting, difficulty in gastric emptying, constipation. On examination, 
the child can be lethargic and may result in respiratory failure and cardiovascular and hemodynamic collapse. ${ }^{[1,5,6,7]}$

NEC is categorized as 3 stages by Bell's staging.

a. Stage 1 (Suspected NEC): presents with signs of mild intensity

b. Stage 2 (Definite NEC): signs of stage 1 along with abdomen discomfort, intestinal obstruction may be present.

c. Stage 3 (Advanced NEC): signs of stage 1 and stage 2 with associated bradycardia, hypotension, respiratory failure, coagulopathy and severe metabolic acidosis. Perforation may occur leading to peritonitis. The main complications following NEC are development of short bowel syndrome, intestinal stenosis, sepsis, need for colostomy, and difficulty in re-establishing the early enteral diet. ${ }^{[6,8,9,10]}$

Diagnosis is usually made clinically as the pathology progresses, where there is presence of blood in stool, abdominal distention, vomiting or gastric stasis, and confirmed by radiological studies. $^{[9,11]}$

If NEC is suspected, oral feeding should be stopped immediately. A nasogastric tube should be inserted to relieve distension and to aspirate stomach contents. IV fluids and electrolytes should be administered. Parenteral nutrition may be administered. The baby is given antibiotics after taking suitable cultures. Shock is managed by replacement of fluids and use of vasopressor agents. In most severe cases, there may be a need for surgical intervention. ${ }^{[6,8,12,13]}$

\section{Conclusion}

Premature children, formula fed infants or who have received blood transfusion are at greater risk of developing NEC. Early diagnosis, bowel rest, antibiotics, and supportive therapy are the mainstays of treatment.

\section{References}

1. Maheshwari A, Corbin LL, Schelonka RL (2011) Neonatal necrotizing enterocolitis. Res Rep Neonatology 1: 39-53.
2. Chu A, Hageman JR, Caplan MS (2013) Necrotizing Enterocolitis: predictive Markers and Preventive Strategies. N Reviews 14: 113120.

3. Anand RJ, Leaphart CL, Mollen KP, Hackam DJ (2007) The Role of The Intestinal Barrier In The Pathogenesis Of Necrotizing Enterocolitis. Shock 27: 124-133.

4. Lin PW, Nasr TR, Stoll BJ (2008) Necrotizing enterocolitis: recent scientific advances in pathophysiology and prevention. Semin Perinatol 32: 70-82.

5. Miyaki M, Steil F, Sarquis AL, Silva R (2007) Apresentaçãoclínica da Enterocolite Necrosante: diagnóstico e prognóstico. Pediatr 29: 192-199.

6. Neves LAT, Mendes E, Neves DB (2009) Enterocolitenecrozante: um desafio para o recém-nascidoprematuro de muitobaixo peso. Rev Med Minas Gerais 19: 51-57.

7. Neu J, Walker AW (2011) Necrotizing Enterocolitis. N Engl J Med 364: 255-264.

8. Garg P (2007) Necrotising Enterocolitis: newer Insights. J Clin Diagn Res 1: 90-103.

9. Souza JCK (2008) Influência da localização da Enterocolite Necrosantena Mortalidade de Recém Nascidos Submetidos à Laparotomia. (Tese de Doutorado). Porto Alegre: UFRGS.

10. Jesse N, Neu J (2006) Necrotizing Enterocolitis: Relationship to Innate Immunity, Clinical Features, and Strategies for Prevention. Neoreviews 7: 143-150.

11. Silva DCB, Quinello C, Pires DA, Pinto JR, Mattar AC, et al. (2008) Uso de fatores de crescimentoepidérmico e estimulador de colônias de granulócitosnaprevenção e tratamento da enterocolitenecrosante no recémnascido. Rev Paul Pediatr 26: 170-175.

12. Miyaki M, Steil F, Sarquis AL, Silva R (2007) Enterocolitenecrosanteemserviço com banco de leitehumano. Pediatr 29: 183-191.

13. Bueno MB, Reis VS (2011) A importância do leitematernonaprevenção da enterocolitenecrosante entre recémnascidos. Nutrire Rev Soc Bras Alim Nutri 36: 266. 